Ayşe Ferhan Akgül, Medine Karataş, Biray Öztürk

\section{Muğla Sıtkı Koçman Üniversitesi Tıp Fakültesi Eğitim ve Araştırma Hastanesi Erişkin Yoğun Bakım Ünitelerinde 5 yıllık Invaziv Araçla İlişkili Hastane Enfeksiyonları Sürveyansı}

\author{
A Five Years' Survey of Device-Associated \\ Nosocomial Infections in Adult Intensive Care Units \\ of Muğla Sıtkı Koçman University Faculty of Medicine \\ Training and Research Hospital
}

Geliș Tarihi/Received: 30.12 .2013

Kabul Tarihi/Accepted: 02.04.2014

Türk Yoğun Bakım Derneği Dergisi, Galenos Yayınevi tarafından basılmıștır.

Journal of the Turkish Society of Intensive Care, published by Galenos Publishing ISSN: 2146-6416

Medine Karataş, Biray Öztürk,

Muğla Sıtkı Koçman Üniversitesi Tıp Fakültesi Eğitim ve Araştırma Hastanesi, Enfeksiyon Kontrol Komitesi, Muğla, Türkiye

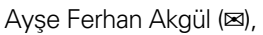

Muğla Sıtkı Koçman Üniversitesi Tıp Fakültesi Eğitim ve Araștırma Hastanesi, Enfeksiyon Hastalıkları ve Klinik Mikrobiyoloji Anabilim Dalı, Muğla, Türkiye

E-posta: ayseferhana@yahoo.com.tr Gsm: +90 5057663399
ÖZET Amaç: Bu çalışmada, Muğla Sıtkı Koçman Üniversitesi Tıp Fakültesi Eğitim ve Araştırma Hastanesi yoğun bakım ünitelerinde (YBÜ), 2008-2012 yılları arasında invaziv araçla ilişkili hastane enfeksiyonu (IAlHE) hızları ve türleri, invaziv araç kullanma oranları (IAKO), etken mikroorganizmaların dağılımları değerlendirilerek, YBÜ'lerimizin kendi içlerindeki değişimlerini ulusal ve uluslar arası veriler ile kıyaslamak, enfeksiyon kontrol komitesinin çalışmalarını değerlendirmek amaçlanmıştır. Gereç ve Yöntem: YBÜ'de yatan tüm hastalar aktif prospektif sürveyans yöntemiyle izlenmiştir. Hastane kökenli enfeksiyon tanıları, Centers for Disease Control tanı kriterlerine göre konulmuştur. IAlHE hızları ve IAKO, National Nosocomial Infection Surveillance System ve Sağlık Bakanlığı Ulusal Hastane Enfeksiyonları Sürveyans Ağı birimlerinin önerilerine göre hesaplanmıştır.

Bulgular: Her iki ünitede de en sık görülen IAlHE türleri, üriner kateterle ilişkili üriner sistem enfeksiyonu (ÜKIÜSE) ve ventilatörle ilişkili pnomoni (VIP) olup, santral venöz kateterle ilişkili kan dolaşımı enfeksiyonu (SVKI-KDE) daha az görülmüştür. Dahiliye YBÜ'de, 5 yıllık hastane enfeksiyonu insidans dansitesi (HEID): 11,48, ÜKI-ÜSE hızI: 9,88, VIP hızl: 7,20, SVKI-KDE hızı: 1,63 iken, Reanimasyon-cerrahi YBÜ'de, 5 yıllık HEID: 6,68 ve ÜKI-ÜSE hızı: 5,17, VIP hızı: 2,39, SVKI-KDE hızı da 1,90 olarak saptanmıştır. Candida spp. ile Gram negatif basiller her iki ünitede de en sık izole edilen etkenler olup, Acinetobacter ve pseudomonas suşlarında karbapenem direnci Türkiye ortalamasına göre düşük bulunmuş, Gram pozitif koklarda vankomisin direnci saptanmamıştır. Sonuç: IAlHE'lerini azaltmak için, YBÜ'lerinde el hijyeni, invaziv araç kullanımının kısıtlanması, kateterizasyon başta olmak üzere asepsiye dikkat edilmesi, fiziksel şartların düzeltilmesi ve antibiyotik kullanımının rasyonalize edilmesi gibi enfeksiyon kontrol önlemlerinin sağlanması gereklidir.

Anahtar Kelimeler: Yoğun bakım ünitesi, hastane kökenli enfeksiyon, invaziv araç kullanımı, ventilatörle ilişkili pnomoni

SUMMARY Objective: In this survey we aimed to assess the investigation results of our hospital's infection control committee and to compare our results with national and international data by assessing invasive device associated nosocomial infection (IDANI) rates, invasive-device utilization ratios (IDUR), types of IDANIs, distribution of causative microorganisms in intensive care units (ICUs) of Muğla Sıtkı Koçman University Medical Faculty Training and Research Hospital between years 2008 and 2012.

Material and Method: All patients admitted to ICUs were taken under examination using active prospective surveillance method. Centers for Disease Control criteria were used for establishing healthcare associated infections (HAI). IDANI rates and IDUR were calculated according to National Nosocomial Surveillance System and National Surveillance Net established by Ministry of Health.

Results: In both of the ICUs (medical and 
surgical, urinary catheter associated-urinary tract infections (UCA-UTI) and ventilator-associated pneumonia (VAP) were the most frequently seen infection types. Central line-associated bloodstream infection (CLA-BSI) occurrence was low in both ICU services. In medical ICU, HAI incidence density was calculated as 11.48, UCA-UTI, VAP and CLA-BSI rates were $9.88,7.20$ and 1.63 , respectively, while in surgical-reanimation ICU, HAI incidence density was 6.68, UCA-UTI, VAP and CLA-BSI rates were 5.17, 2.39 and 1.90 , respectively for the five years period. Candida spp. and Gram-negative bacilli were the frequently isolated microorganisms in both units. In Acinetobacter and

\section{Giriş}

Yoğun bakım ünitesinde (YBÜ) izlenen hastaların; yaşamı tehdit eden primer hastalıklarının yanı sıra, eșlik eden komplikasyonlar, çok sayıda invaziv girişim uygulanması, geniş spektrumlu antibiyotiklerin kullanımı, uzun süreli yatış, cerrahi operasyonlar gibi nedenlerden dolayı hastane kökenli enfeksiyon (HKE) insidansı yüksektir ve tüm HKE'lerin \%25'i YBÜ'de gelişmektedir (1-3). HKE'ler morbidite ve mortaliteyi olumsuz etkilemekte, yatış süresini ve ek tıbbi bakım gereksinimini artırarak maliyeti de artırmaktadır $(1,4,5)$.

HKE'lerin sıklığının ve özelliklerinin değerlendirilebilmesi, ancak etkin bir sürveyans programının uygulanması ile mümkündür (2). Hastaneler bu veriler sayesinde yürüttükleri enfeksiyon kontrol programlarının (EKP) etkinliğini değerlendirebilmekte, kendi hastaneleriyle diğer hastanelerin, yıllar içinde ve bölümleri arasında kıyaslamalarını yapabilmektedirler. Sürveyansa dayalı doğru bir EKP ile HKE ve invaziv araçla ilişkili hastane enfeksiyonu (IAlHE) hızlarının önemli oranda azaltılabileceği gösterilmiştir $(3,6)$. Sürveyans sonuçları, kalite göstergesi olarak da son derece önemlidir (3).

Tüm hastaneyi kapsayan sürveyans çalışmaları, çok fazla zaman, insan gücü ve maliyet gerektirdiği gibi, bu yolla saptanan enfeksiyon hızlarının kıyaslama amacıyla yüksek bir doğrulukta kullanılabilir olmadığı anlaşımıştır (2). Çalışmalar, YBÜ enfeksiyon hızlarını hastane içi ve hastaneler arasında kıyaslamada en doğru yolun, invaziv araç kullanımı ile ilişkili enfeksiyon hızlarının, yoğun bakım günü ve invaziv araçlı gün bazında değerlendirilmesi olduğunu göstermektedir $(2,3,6)$. Centers for Disease Control (CDC) ve National Nosocomial Infection Surveillance (NNIS) tarafından önerilen formüllere göre hesaplanmış hastane enfeksiyonu insidans dansitesi (HEID) ve IAlHE hızları, benzer kurumlar arasında karşılaştırma yapmada iyi bir ölçüt olmuştur (3,6-11). Sağlık Bakanlığı Ulusal Hastane Enfeksiyonları Surveyans Ağı (UHESA) birimi tarafından açıklanan yıllık surveyans raporları da ülkemizdeki hastane gruplarının birbirini tanıyabilmesini ve kıyaslayabilmesini sağlamıştır (12-15).

YBÜ'lerinde sıklıkla kullanılan geniş spektrumlu antibiyotikler, ünite içinde dirençli mikroorganizmaların seçilmesine neden olmakta ve bu organizmalarla gelişen pseudomonas strains, carbapenem resistance was lower than the average of Turkey. There was no resistance to vancomycin for Grampositive cocci.

Conclusion: Infection control measurements such as hand washing limitation of invasive device utilization, strict application of antisepsi especially catheter using, improving the environmental conditions and prudent use of antibiotics are necessary for minimizing IDANIs.

Key Words: Intensive care unit, healthcare associated infection, invasive device utilization, ventilator associated pneumonia

IAlHE'leri de morbidite ve mortaliteyi artırmaktadır. Bu nedenle IAlHE türlerinin ve etken mikroorganizmalar ile bunların antibiyotik direnç durumlarının sürekli izlenerek emprik antibiyotik kullanım politikalarının belirlenmesi ve güncellenmesi önem kazanmaktadır.

Bu çalışmada, 01/01/2008 ile 31/12/2012 tarihleri arasında Muğla Sıtkı Koçman Üniversitesi Eğitim ve Araştırma Hastanesi'nin (MSKÜEAH) iki erişkin YBÜ'de, aktif prospektif surveyans ile izlenen hastalarda gelişen HKE'ler, HEID ve IAlHE hızları, invaziv araç kullanma oranları (IAKO) ile IAlHE türlerinin ve etkenlerinin dağılımlarını belirlemek ve aynı yöntemle sürveyans yapan hastanelerle verilerimizi kıyaslamak, beş yıllık sürede EKK'mızın çalışmalarını değerlendirmek amaçlanmıştır.

\section{Gereç ve Yöntem}

MSKÜEAH, çalışmanın yapıldığı yıllarda Muğla Devlet Hastanesi adıyla hizmet veren, 501 yataklı ikinci basamak yataklı tedavi kurumu iken, günümüzde, afiliasyon uygulamasına geçilerek üçüncü basamak üniversite-eğitim hastanesine dönüşmüş bir hastanedir. Çalışmanın yapıldığı sürede, erişkin dahiliye YBÜ (DYBÜ); 6 yataklı, çoğunlukla nöroloji, dahiliye, göğüs hastalıkları ve nefroloji hastalarının izlendiği, reanimasyon-cerrahi YBÜ (RCYBÜ) ise, 8 yataklı ve sıklıkla genel cerrahi, beyin cerrahi ve diğer cerrahi branşların pre ve/veya postoperatif dönemdeki hastalarıyla, mekanik ventilasyon gerektiren ve anestezi-reanimasyon uzmanlarınca izlenen hastaların yatııılığı ikinci basamak, açık tipte YBÜ'leridir. Her iki ünitede de merkezi havalandırma ve hepa filtre sistemi ile izolasyon odası bulunmamakta, diğer fiziki şartlar da standartların altındadır. Enfeksiyon kontrol komitesi'nde (EKK), sertifikalı ve en az 3 yıl deneyimli iki enfeksiyon hemşiresi $(E H)$ ve bir enfeksiyon kontrol hekimi (EKH) görev yapmaktadır.

Bu çalışmada, 01/01/2008 ile 31/12/2012 tarihleri arasında iki erişkin YBÜ'de 48 saat ve üzerinde yatan, 14 yaş üstü hastalarda gelişen IAlHE'leri ve etken mikroorganizmalar değerlendirildi. YBÜ'lerinde, hastaya ve laboratuvara dayalı aktif prospektif surveyans yapıldı. NNIS ve UHESA tarafından önerilen, hastanemize adapte edilmiş günlük ve aylık erişkin 
hasta izlem formları kullanılarak, HKE tanısı alan ve almayan tüm hastaların verileri kaydedildi. YBÜ'ye dış hastanelerden gelen hastalarda ilk yatışta, bunun dışında tüm hastalarda haftanın belli iki gününde $\mathrm{CRP}$, tam idrar, trakeal aspirat (kalitatif) ve idrar kültür antibiyogram testleri, ateş $38^{\circ} \mathrm{C}$ ve üzerinde olduğunda da periferden ve varsa kateterden kan kültürleri ile gerekli durumlar haricinde haftada bir kez rutin akciğer grafisi alındı. Gerektiğinde antibiyotik kullanılması, değiştirilmesi veya sonlandırıması kararı sadece aynı EKH tarafından verildi.

Enfeksiyon kontrol ekibi tarafından günlük vizitler ile, hastaların yaş, cinsiyet, yatış tanıları, altta yatan hastalıkları, immünsüpresif-H2 antagonisti kullanımı, hemodiyaliz, enteral beslenme, bası yaraları vb. gibi bağışıkığı etkileyen durumları, operasyon varlığı, yoğun bakımda kalış süreleri, santral venöz kateter, üriner kateter, mekanik ventilatör (invaziv veya noninvaziv) kalış süreleri ve uygulanma yolları, hastalıkların şiddetleri standart formlara kaydedildi. Hastalıkların şiddetini değerlendirmede APACHE skorlaması yerine, CDC-NNIS sistem kriterlerine dayanılarak belirlenmiş olan ASIS (average severity of ilness score) yöntemi kullanıldı (3). Bu skorlamada; 1 puan: sadece rutin gözlem için yatan postoperatif hastalar, 2 puan: fizyolojik olarak stabil, gözlem için yatan cerrahi dışı hastalar, 3 puan: devamlı hemşire bakımı ve monitorizasyon gereken hastalar, 4 puan: fizyolojik olarak stabil olmayan, yoğun hemşire ve medikal bakım gerektiren, sıklıkla yeni girişim ve tedaviler eklenebilen hastalar, 5 puan ise; fizyolojik olarak stabil olmayan, aynı zamanda şok veya komada olan, kardiyopulmoner resüsitasyon gerekebilecek, yoğun hemşire ve medikal bakım gereken sıklıkla durumu değişebilecek hastalara verildi. Hastaların tüm fizik muayene ve laboratuvar sonuçları, kültür antibiyogram sonuçları, bu sonuçlara göre enfeksiyon kontrol hekimince düzenlenen antibiyotiklerin doz ve kullanım süreleri, HKE tanısı alıp almadıkları ile hastaların akibetlerinin eksiksiz doldurulduğu formlar; haftada iki kez ve her ay sonu enfeksiyon kontrol ekibince değerlendirilip hesaplamalar yapıldıktan sonra, her iki üniteye aylık geri bildirim yapıldı.

HKE'lerinin tanımlanmasında CDC tanı kriterleri kullanıldı (16). HEID, IAIHE hızları, IAKO'ları; NNIS tarafından belirlenen formüller kullanılarak hesaplandı (7-11). NNIS raporları ile kıyaslama yapıııken; DYBÜ için nöroloji, iç hastalıkları, 15 yataktan fazla yatak sayılı ve medikal hastaların yattığ birimlerin YBÜ, RCYBÜ için ise anestezi, reanimasyon, cerrahi, beyin cerrahi ve travma birimlerinin YBÜ değerleri, UHESA ile kıyaslanırken ise, Sağlık Bakanlığı'na bağlı Devlet hastanelerinin YBÜ değerleri esas alındı (7-15).

Mikroorganizmaların izolasyonu, tanımlanması ve duyarlıık testleri için standart yöntemler kullanıldı.

Çalışmanın ilk iki yılında her iki YBÜ'de de üriner kateterizasyonda kapalı sistem drenaj kullanılmıyor ve mekanik ventilatörlerin ayrılabilinir kısımları her hastadan sonra ünite içinde yüksek dezenfeksiyon ve durulama yapılarak asılma şeklinde kurutulduktan sonra yeniden kullanılıyor iken, 2010 yılından itibaren üriner kateterizasyonda kapalı drenaja ve mekanik ventilasyonda ise disposibl kullanıma geçildi. Çalışmanın yapıldığı son iki yılda her iki ünitede fiziki şartlarda düzelmeler (DYBÜ'de lambrilerin kaldırılarak duvarların ve zeminlerin antibakteriyel malzemeyle kaplanması, her iki üniteye de lavabolar eklenmesi, aspiratör haznelerine disposibl torbaların alınması, hastalar arası seperasyonlar ile kısmi izolasyon sağlanması gibi) gerçekleştirildi. Yine çalışma süresince, EKK tarafından hastanemiz şartlarına göre düzenlenmiş Sağlık Bakanlığı referanslarından elde edilen ventilatörle ilişkili pnomoni, üriner kateterle ilişkili üriner sistem enfeksiyonları ve santral venöz kateterle ilişkili kan dolaşımı enfeksiyonları önleme programları uygulanırken, son iki yılda eğitim ve denetimlerin sıklaştıııması ile bu programlara uyum arttırıld.

Tablo 1. Her iki YBÜ'de yıllara göre toplam izlenen hasta sayıları, toplam YBG sayıları, IAiHE gelişen hasta sayıları, atak sayıları ile HKE hızları ve HEiD'leri

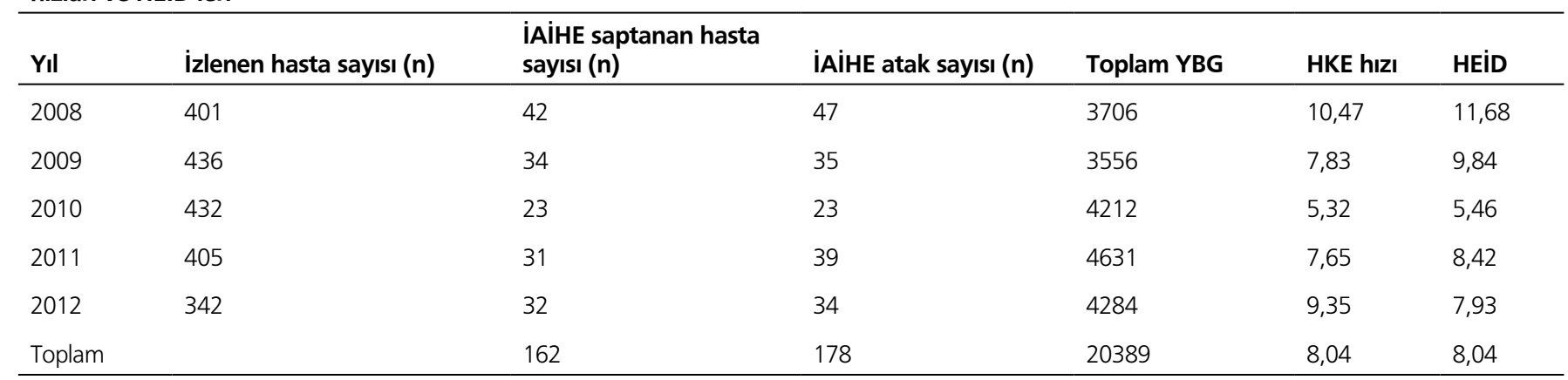

YBÜ: Yoğun bakım ünitesi, YBG: Yoğun bakım günü, IAiHE: İnvaziv araçla ilişkili hastane enfeksiyonu, HKE hızı= IAiHE gelişen hasta sayısı/toplam izlenen hasta sayısıx100, HEiD: Hastane enfeksiyonu insidans dansitesi, HEID= IAIHE atak sayısı/toplam izlem yapılan YBG sayısıx1000 $(11,15)$. 


\section{Bulgular}

2008-2012 yılları arasında, erişkin DYBÜ ve RCYBÜ'de toplam 20389 yoğun bakım gününde (YBG) izlenen 2014 hastanın 162'sinde, 178 invaziv araçla ilişkili hastane enfeksiyonu atağı saptanmış olup YBÜ'lerimizin ortak hastane kökenli enfeksiyon hızı: \%8,04 ve hastane enfeksiyonu insidans dansitesi: 8,73/1000'dir. Yıllara göre her iki YBÜ'de izlenen hasta sayıları, invaziv araçla ilişkili hastane enfeksiyonu saptanan hasta sayıları, atak sayıları, YBG sayıları ile hastane kökenli enfeksiyon hızları ve hastane enfeksiyonu insidans dansiteleri Tablo 1'de gösterilmiştir. DYBÜ'de 5 yll süresince, toplam 8707 YBG'de, 92 hastada, 100 IAlHE atağı saptanmış olup, 5 yıllık HEID: 11,48 iken, RCYBÜ'de aynı süre içinde 11692 YBG'de 70 hastada 78 atak ile, HEID: 6,67 olarak bulunmuştur (Tablo 2).

Her iki YBÜ içinde hastane kökenli enfeksiyon gelişen hastaların \%47'si kadın , \%53'ü erkek (DYBÜ'de K/E: 1, RCYBÜ'de K/E: 43/57), yaş dağılımına bakıldığında, DYBÜ'de HKE'li hastaların \%92'si 60 yaş üstü, \%6'sı 20-60 yaş arası, $\% 2$ 'si 20 yaş altı iken, RCYBÜ'de \%67'si 60 yaş üstü, \%24'ü 20-60 yaş arası ve \% 9'u da 20 yaş altında bulunmuştur. YBÜ'ye yatış tanıları açısından, DYBÜ'de ilk sırada serebrovasküler hastalıklar ikinci sıklıkta solunum sistemi hastalıkları-solunum yetmezliği, üçüncü olarak da metabolik hastalıklar-GIS hastalıkları ve zehirlenmeler gurubu (sırasıyla \%35-\%30-\%30) gözlenmiştir. RCYBÜ'de ise, ilk sırada travma-operasyonlar (\%34) gelirken, solunum yetmezliği \%22, serebrovasküler hastalıklar ve kanamalar \%18, metabolik hastalıklar-GIS hastalıkları \%16 sıklıkta görülmüştür. Altta yatan hastalıklara bakıldığında DYBÜ'de HKE tanılı hastaların \%96'sında ileri yaş, \%42'sinde nörolojik hastalıklar, \%38'inde $\mathrm{KOAH}$ ve diğer solunum yolları hastalıkları, \%38'inde diabetes mellitüs, \%37'sinde kardiyak sorunlar, \%9'unda malignite ve \%4'ünde ise böbrek yetmezliğinin eşlik ettiği görülmüştür. RCYBÜ'de ise HKE'li hastaların \%40'ında ileri yaş, \%34'ünde travma ve operasyon, \%24'ünde solunum yolu hastalıkları, \%19'unda ise nörolojik hastalıklar altta yatan hastalıklar olarak saptanmıştır. ASIS skorlaması ile hastalıkların şiddeti incelendiğinde, DYBÜ'de HKE tanısı alan hastaların \%82'si ASIS 2 ve 3 puanda (\%33 ve \%49) iken, RCYB'de hastaların $\% 72$ 'si ASIS 3 ve 4 puanda (\%30 ve $\% 42$ ), toplanmıştır. ASIS 5 puanlı hasta oranı DYBÜ'de \%6, diğer ünitede ise \%12 olarak bulunmuştur.

DYBÜ'de ortalama yatış süresi 42,57 gün, diğer ünitede ise 41,15 gündür. Her iki YBÜ'de de ÜKI-ÜSE gelişen hastaların \%99'unda üriner kateter olup ortalama üriner kateter kalış süresi 16,7 gün iken, yine iki ünitede de VIP olgularını \%100'ünde mekanik ventilasyon mevcut olup (\%89'u invaziv, \%11'i non invaziv), bu hastalarda mekanik ventilatörün ortalama kalış süresi: \% 42,55 gündür. Iki YBÜ'de de SVKI-KDE saptanan hastaların ortalama SVK kalış süreleri 30,75 gün olup, santral venöz kateterlerin \%20'sini femoral, $\% 80$ 'ini ise subklaviyen veya jügüler kateterlerin oluşturduğu görülmüştür.

DYBÜ'de 5 yıllık ÜKI-ÜSE, VIP ve SVKI-KDE hızları, invaziv araç kullanma oranları ile sonuçların NNIS ve UHESA persentilleri ile kıyaslamaları Tablo 3'de, RCYBÜ'deki sonuçlar ve kıyaslamaları ise Tablo 4'de gösterilmiştir. DYBÜ'de ÜKIÜSE hızı 5 yıl boyunca NNIS ve UHESA'ya göre, ÜKKO'da

Tablo 2. DYBÜ ve RCYBÜ'de yıllara göre saptanan IAIHE atakları ile HEiD'leri

\begin{tabular}{|c|c|c|c|c|c|c|c|}
\hline Yillar & & 2008 & 2009 & 2010 & 2011 & 2012 & Toplam \\
\hline DYBÜ'de izlem yapılan YBG & & 1680 & 1525 & 1694 & 1791 & 2017 & 8707 \\
\hline DYBÜ'de IAIHE atak sayısı (n) & & 29 & 22 & 12 & 19 & 18 & 100 \\
\hline \multirow[t]{3}{*}{ DYBÜ'de IAIHE türleri } & ÜSE & 25 & 19 & 11 & 15 & 13 & 83 \\
\hline & ViP & 3 & 2 & 1 & 2 & 5 & 13 \\
\hline & $\mathrm{KDE}$ & 1 & 1 & 0 & 2 & 0 & 4 \\
\hline DYBÜ için HEID & & 17,26 & 4,42 & 7,08 & 10,60 & 8,92 & 11,48 \\
\hline DYBÜ'de izlem yapılan YBG & & 2036 & 2031 & 2518 & 2840 & 2267 & 11692 \\
\hline RCYBÜ'de IAiHE atak sayısı(n) & & 18 & 13 & 11 & 20 & 16 & 78 \\
\hline \multirow[t]{3}{*}{ RCYBÜ'de IAIHE türleri } & ÜSE & 13 & 13 & 8 & 13 & 12 & 59 \\
\hline & ViP & 4 & 0 & 3 & 3 & 1 & 11 \\
\hline & $\mathrm{KDE}$ & 1 & 0 & 0 & 4 & 3 & 8 \\
\hline RCYBÜ için HEID & & 8.88 & 6.40 & 4.36 & 7.04 & 7.05 & 6.67 \\
\hline
\end{tabular}

YBG: Yoğun bakım günü, IAiHE: İnvaziv araçla ilişkili hastane enfeksiyonu, HEiD: Hastane enfeksiyonu insidans dansitesi, HEiD= iAiHE atak sayısı/toplam izlem yapılan YBG sayısıx1000 (11,15). DYBÜ: Dahiliye yoğunbakım ünitesi,RCYBÜ: Reanimasyon cerrahi yoğun bakım ünitesi. ÜSE: üriner sistem enfeksiyonu,VIP: ventilatörle ilişkili pnomoni, KDE: kan dolaşımı enfeksiyonu. 
NNIS'ye göre 90 persentil ve üzerinde bulunmuştur. VIP hızı 5 yıl boyunca NNIS'ye göre 90 üzerinde iken, VKO 50 ve altında olarak saptanmıştır. Aynı ünitede SVKKO'nun 5 yıl boyunca 50 persentilin üzerine çıkmadığı, SVKI-KDE'nin ilk 2 yıl 75-90 arasında iken, üçüncü yıl 10-25'e indirildiği, dördüncü yıl ise araç kullanma oranındaki artışa (75-90) paralel olarak yeniden 90 persentile yükseldiği görülmüştür (Tablo 3).

RCYBÜ'de ise, ÜKKO'ları NNIS'ye göre çalışma süresince 90 persentil üzerinde (UHESA'ya göre 50-75 arasında) iken, ÜKI-ÜSE hızları her iki birimin raporlarında da 75 persentil civarında bulunmuştur. VKO'ları her iki birimin raporlarında da 5 yıl boyunca 25-50 arasında iken, VIP hızlarının UHESA'ya göre düşük (10-25) ama NNIS'ye göre (2009 hariç) 50-75 arasında olduğu görülmüştür (Tablo 4). Aynı ünitede SVKKO'ları ise ilk 3 yılda düşük, son iki yılda 50-75 civarına yükseldiği, SVKKDE'nin de buna paralel olarak son iki yıl ortalamanın üzerine çıktığı görülmüştür.

DYBÜ ve RCYBÜ'de 5 yılda saptanan ÜKI-ÜSE ataklarında elde edilen etkenlerin dağılımı incelendiğinde, toplam 142
ÜKI-ÜSE atağının \%58'i DYBÜ'de görülmüştür. Yüz kırk iki suş içinde; Enterobacteriacea türleri \%42, Candida türleri $\% 32$, Pseudomonas ve Acinetobacter türleri \%16, Gram pozitif koklar da \%6 sıklıkta saptanmıştır (Tablo 5).

DYBÜ ve RCYBÜ'de 5 yılda saptanan VIP ataklarında elde edilen etkenlerin dağılımı Tablo 6'de gösterilmiştir. Acinetobacter ve Pseudomonaslar dahil Gram negatif basillerin çoğunlukta olduğu (19/24) bunların daha ağırlıklı olarak DYBÜ'de saptandığı (11/19) görülmüştür.

DYBÜ ve RCYBÜ'de SVKI-KDE ataklarında elde edilen etkenlerin dağılımı incelendiğinde, koagulaz pozitif ve negatif stafilokokların ağırlıkta olduğu (8/12) görülmüştür (Tablo 7).

Her iki YBÜ'de 5 yıl boyunca saptanan IAlHE ataklarına göre etkenlerin dağıımı Tablo 8'de gösterilmiştir. Toplam 178 etkenin \%80'i ÜKI-ÜSE, \%13'ü VIP ve \%7'si de SVKI-KDE ataklarında saptanmış olup etkenlerin \%59'unu Gram negatif basiller oluşturmuştur.

Her iki YBÜ'de saptanan etkenlerin bazı antibiyotiklere direnç durumları Tablo 9'da görülmektedir. Acinetobacter

Tablo 3. DYBÜ'de 5 yıllık ÜKi-ÜSE, viP, SVKi-KDE hızları, IAKO'ları, NNIS ve UHESA persentilleri ile kıyaslamaları

\begin{tabular}{|c|c|c|c|c|c|c|}
\hline Yıllar & ÜKi-ÜSE hızı & ÜKKO & ViP hızı & VKO & SVKI-KDE hızı & SVKO \\
\hline NNIS(a) & $>90$ & $>90$ & $>90$ & 10 & $75-90$ & 10 \\
\hline UHESA(b) & $>90$ & $25-50$ & $>90$ & 10 & 50 & 25 \\
\hline 2009 & 12,62 & 0,98 & 17,24 & 0,07 & 2,95 & 0,22 \\
\hline 2010 & 6,63 & 0,98 & 3,56 & 0,17 & - & 0,18 \\
\hline NNIS & $>90$ & $>90$ & $>90$ & $<10$ & $10-25$ & $<10$ \\
\hline UHESA & $50-75$ & $50-75$ & $25-50$ & $25-50$ & $10-25$ & $25-50$ \\
\hline 2012 & 6,69 & 0,96 & 6,82 & 0,36 & - & 0,38 \\
\hline NNIS & $75-90$ & $>90$ & 90 & 50 & $10-25$ & 25 \\
\hline UHESA & $75-90$ & 50 & $25-50$ & 75 & 25 & $50-75$ \\
\hline Toplam & 9,88 & 0,96 & 7,20 & 0,21 & 1,63 & 0,28 \\
\hline
\end{tabular}

ÜKi-ÜSE: Üriner kateterle ilişkili üriner sistem enfeksiyonu,

ÜKI-ÜSE hızı= Üriner kateterle ilişkili ÜSE atak sayısı/üriner kateter günüx1000 $(11,15)$.

ÜKKO: Üriner kateter kullanma oranı, ÜKKO= Üriner kateter günü/YBG $(11,15)$.

ViP: Ventilatörle ilişkili pnomoni, ViP hızı= ViP atak sayısı/ventilatör günüx1000 $(11,15)$.

VKO: Ventilatör kullanma oranı, VKO= Ventilatörlü gün/YBG $(11,15)$.

SVKI-KDE: Santral venöz kateterle ilişkili kan dolaşımı enfeksiyonu, SVK-KDE hızı= SVKi-KDE atak sayısı/SVK günüx1000 $(11,15)$

SVKO: Santral venöz kateter kullanma oranı, SVKO= Santral venöz kateter günü/YBG $(11,15)$.

(a).National Nosocomial Infection Surveillance(NNIS)raporlarına göre persentil (7-11).

(b).Ulusal Hastane Enfeksiyonları Surveyans Ağı (UHESA) raporlarına göre persentil (12-14). 


\begin{tabular}{|c|c|c|c|c|c|c|}
\hline Yıllar & ÜKII-ÜSE hıZı & ÜKKO & ViP hızı & VKO & SVKi-KDE hıZı & SVKO \\
\hline 2008 & 6,61 & 0,97 & 7,22 & 0,27 & 2,59 & 0,19 \\
\hline NNIS(a) & 75 & $>90$ & 75 & $10-25$ & $50-75$ & $<10$ \\
\hline UHESA(b) & 75 & 50 & 25 & 25 & $<50$ & 25 \\
\hline 2009 & 6,50 & 0,98 & - & 0,34 & - & 0,28 \\
\hline NNIS & $75-90$ & $>90$ & 10 & $25-50$ & 10 & 10 \\
\hline UHESA & 75 & 50 & $<10$ & 25 & $<50$ & 25 \\
\hline 2010 & 3,26 & 0,97 & 3,23 & 0,37 & - & 0,29 \\
\hline NNIS & 75 & $>90$ & 50 & $25-50$ & $<25$ & $<10$ \\
\hline UHESA & $50-75$ & $50-75$ & $10-25$ & 25 & $<25$ & $10-25$ \\
\hline 2011 & 4,69 & 0,97 & 2,34 & 0,45 & 2,68 & 0,52 \\
\hline NNIS & 75 & $>90$ & $50-75$ & 75 & $75-90$ & 50 \\
\hline UHESA & 75 & 50 & $10-25$ & 50 & $50-75$ & $50-75$ \\
\hline 2012 & 5,40 & 0,98 & 0,87 & 0,51 & 2,90 & 0,45 \\
\hline NNIS & 90 & $>90$ & 50 & $75-90$ & 90 & $25-50$ \\
\hline UHESA & $50-75$ & 50 & $<10$ & 50 & $50-75$ & 50 \\
\hline Toplam & 5,17 & 0,97 & 2,39 & 0,39 & 1,90 & 0,36 \\
\hline
\end{tabular}

ÜKi-ÜSE: Üriner kateterle ilişkili üriner sistem enfeksiyonu,

ÜKi-ÜSE hIZI= Üriner kateterle ilişkili ÜSE atak sayıs//üriner kateter günüx1000 $(11,15)$.

ÜKKO: Üriner kateter kullanma oranı, ÜKKO= Üriner kateter günü/YBG $(11,15)$.

ViP: Ventilatörle ilişkili pnomoni, ViP hızı= ViP atak sayısı/ventilatör günüx1000 $(11,15)$.

VKO: Ventilatör kullanma oranı, VKO= Ventilatörlü gün/YBG $(11,15)$.

SVKI-KDE: Santral venöz kateterle ilişkili kan dolaşımı enfeksiyonu, SVK-KDE hızI= SVKi-KDE atak sayısı/SVK günüx1000 $(11,15)$.

SVKO: Santral venöz kateter kullanma oranı, SVKO= Santral venöz kateter günü/YBG $(11,15)$.

· (a).National Nosocomial Infection Surveillance(NNIS)raporlarına göre persentil (7-11).

· (b).Ulusal Hastane Enfeksiyonları Surveyans Ağı(UHESA) raporlarına göre persentil (12-14)

türlerinde imipenem direncinin yüksek (\%60), bunun dışındaki Gram negatif basillerde \%0-\%28 arasında olduğu (Pseudomonas spp.de \%13), Pseudomonas türleri (\%47) dışında diğer Gram negatif basiller ve stafilokok türlerinin ciprofloksasin'e yüksek oranda dirençli (\%70 ve 100) olduğu, E. coli, MRSA ve metisiline duyarlı koagulaz negatif stafilokoklarda amikasin direnci düşük (\%0-\%43 arasında) iken diğer türlerde aminoglikozid direncinin yüksek olduğu görülmüştür. Gram pozitif koklarda antibiyotiklere yüksek oranda direnç saptanmış, tüm Gram pozitif suşlar vankomisine duyarlı bulunmuştur.

\section{Tartışma}

Yoğun bakım ünitelerinde uygulanan pek çok invaziv işlemler, kullanılan medikal ajanlar ve antibiyotikler, uzun süreli yatış gibi pek çok faktör HKE gelişme riskini artırımaktadır. Avrupa'da 17 ülkede YBÜ'de gerçekleştirilen bir nokta sürveyans çalışmasında, hastaların \%21'inde, ülkemizde 22 üniversite hastanesi YBÜ'lerinde yapılan benzer çalışmada ise hastaların \%49'unda en az bir HKE saptandığı bildirilmiştir $(17,18)$. Ülkemizde yapılmış bazı çalışmalarla bizim çalışmamızda saptanan, YBÜ'lerindeki HKE hızları Tablo 10'da gösterilmiştir (19-26). Sonuçlarımızın, daha komplike hastaların yattığı, daha fazla invaziv girişim ve yoğun antibiyotik kullanımı olan üniversite ve eğitim-araştırma hastanelerine göre daha düşük, benzer Devlet Hastaneleri ile uyumlu bulunması beklenen bir sonuç olarak gözükmektedir.

Sürveyans, hastanelerin kendi bölümleri içinde HKE hızlarının ve etkenlerinin dağılımlarını belirlemek, erken tanı ve salgın önleme mekanizmalarını hızla çalıştırabilmek, antibiyotik kullanım stratejilerini belirleyebilmek, EKK'larının çalışmalarını değerlendirerek kendi sonuçları ile benzer hastaneleri kıyaslayabilmek olanaklarını sağlayan çok önemli bir süreçtir ve en önemli kalite göstergelerindendir $(2,6)$.

Hastane genelinde enfeksiyon hızlarının izlenmesinin kıyaslama yapmada doğru sonuçlar vermediği anlaşılmıştır. CDC-NNIS ve UHESA referanslarında, aynı risklere maruz 


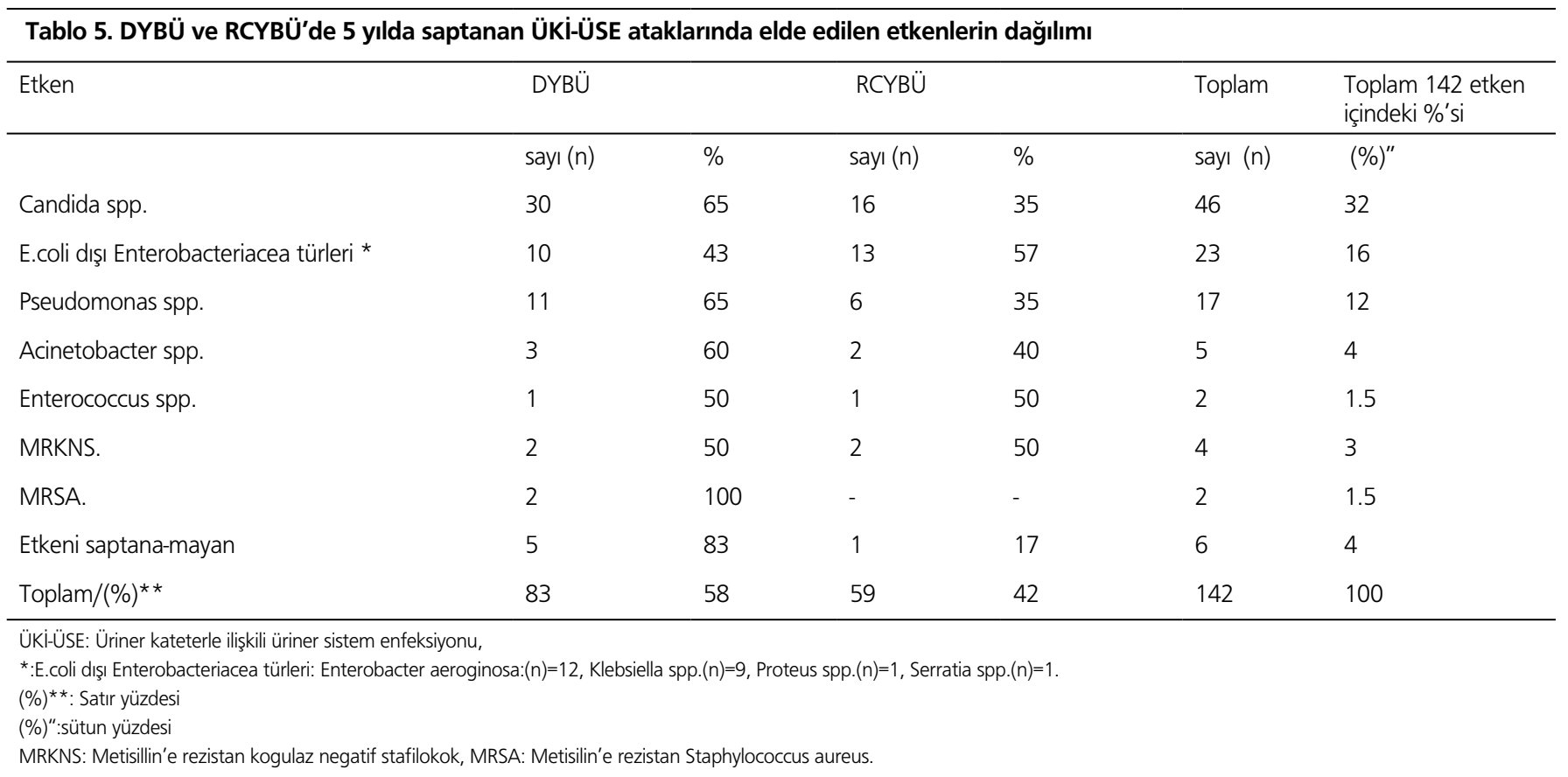

\begin{tabular}{llll}
\hline $\begin{array}{l}\text { Tablo 6. DYBÜ ve RCYBÜ'de } 5 \text { yılda saptanan ViP ataklarında } \\
\text { elde edilen etkenlerin dağılımı }\end{array}$ & DYBÜ & RCYBÜ & Toplam \\
\hline Etken & sayı & sayı & sayı \\
\hline & 3 & 1 & 4 \\
E.coli & 1 & 2 & 3 \\
$\begin{array}{l}\text { E.coli dısıı Enterobacteriacea } \\
\text { türleri* }\end{array}$ & 2 & 3 & 5 \\
Pseudomonas spp. & 5 & 2 & 7 \\
Acinetobacter spp. & 1 & 1 & 2 \\
MRKNS. & 1 & 2 & 3 \\
MRSA. & $13 / 54$ & $11 / 46$ & 24 \\
Toplam:n/(\%)** & & & \\
ViP: Ventilatörle ilişkili pnomoni & & & \\
\hline
\end{tabular}

*: E.coli dışı Enterobacteriacea türleri: Enterobacter aeroginosa: $(n)=1$, Citrobacter freundii: $(n)=1$, Klebsiella spp.: $(n)=1$.

$(\%)^{* *}$ : Satır yüzdesi,

MRKNS: Metisillin'e rezistan kogulaz negatif stafilokok, MRSA: Metisilin'e rezistan Staphylococcus aureus.

kalan hastaların, maruz kaldığı risk günleri bazında formüller ile hesaplanarak kıyaslamanın en doğru yaklaşım olduğu bildirilmekte ve bu formüller tanımlanmaktadır $(7-15,24)$. Ülkemizde yapılan bazı çalışmalarla bizim çalışmamızda bu formüllerle hesaplanmış HEID'leri Tablo 11.de gösterilmiştir (27-29). Sonuçlarımızın, hasta profili ve girişimsel işlemlerle, invaziv araç kullanım oranlarının nispeten azlı̆ı ve hemşire/ hasta oranlarının nispeten yüksek olması gibi sebeplerden ötürü üniversite ve üçüncü basamak eğitim hastanelerine göre daha düşük, benzer fiziki ve beşeri şartlara sahip ikinci basamak hastanelerle yakın olduğu görülmektedir.

Çalışmamızda saptanan IAlHE türleri ve araç kullanma oranlarının DYBÜ ve RCYBÜ'de yıllar içindeki dağılımları ve sonuçların NNIS ve UHESA persentilleri ile kıyaslanması değerlendirildiğinde (Tablo 3 ve 4); DYBÜ'de ÜKI-ÜSE hızlarımız çalışma süresince NNIS ve UHESA ya göre 75->90 persentil arasında, benzer şekilde ÜKKO'larımız da NNIS'e göre 5 yıl için >90, UHESA'ya göre ise 25-75 arasında bulunmuştur. Hastanemizle benzer fiziki sıkıntıların yaşandığı hastanelerin YBÜ'de, endikasyonu bittiği halde hasta bakımında görece kolaylık nedeni ile üriner kateterizasyonun gereğinden uzun sür(dürül)mesi, ÜKIÜSE hızlarının beklenenden yüksek seyretmesine yol açmaktadır. RCYBÜ'müzde de benzer sebeplerden ötürü çalışma boyunca ÜKKO'ları NNIS ve UHESA'ya göre 50-90 arasında ve ÜKI-ÜSE hızları da 75 persentilde seyretmiştir. Hastanemizi kendi içinde değerlendirdiğimizde; çalışmanın yapıldığı ilk 2 yıl, her iki ünitede de kapalı kateterizasyon uygulanılmayıp, üçüncü yıldan sonra bu sisteme geçilmesi ile (ÜKKO'ları düşürülememesine rağmen) son 3 yıl ÜKI-ÜSE hızlarının azaldığı görülmüştür.

Ventilatör kullanma oranlarımız, DYBÜ için ilk iki yıl çok düşük (<10) ama VIP hızlarımız oldukça yüksek (75->90) iken, sonraki yıllarda kullanma oranlarının ortalamaya yaklaştığı, VIP hızlarınında ortalamanın altına indiği görülmüştür (Tablo 3). Bunun sebebi, ilk iki yıl ventilatörlerin ayrılabilinir parçalarının her hastadan sonra çıkarılarak ünite içinde 
dezenfeksiyon yapılıp asılarak kurutulduktan sonra tekrar kullanılması şeklindeki yanlış uygulamadan son 3 yıl içinde vazgeçilerek, klavuzlarda önerilen uygulamalara geçilmesi olduğu düşünülmüştür. RCYBÜ'de de son 3 yıl VKO daha yükselmesine karşın, VIP hızlarının aynı düzeltici çalışmaların sonucu olarak düşük (10-25-50) seyrettiği görülmüştür (Tablo 4). SVKKO'larımız; DYBÜ'de ilk iki yıl çok düşük, tersine SVKIKDE hızları orta ve üzerinde iken, son iki yıl araç kullanma oranı belirgin artmasına rağmen, olgu sayıları çok azalmıştır.

\begin{tabular}{llll}
\hline \multicolumn{4}{l}{$\begin{array}{l}\text { Tablo 7. DYBÜ ve RCYBÜ'de } 5 \text { yılda saptanan SVKi-KDE } \\
\text { ataklarında elde edilen etkenlerin dağılımı }\end{array}$} \\
\hline Etken & DYBÜ & RCYBÜ & Toplam \\
& Sayı & Sayı & Sayı \\
E.coli & 1 & 1 & 2 \\
Pseudomonas spp. & - & 1 & 1 \\
Acinetobacter spp. & - & 1 & 1 \\
MRKNS. & 2 & 1 & 3 \\
MDKNS & - & 1 & 1 \\
Toplam: $/(\%)^{* *}$ & $4 / 33$ & $8 / 67$ & 12 \\
\hline
\end{tabular}

SVKi-KDE: Santral venöz kateterle ilişkili kan dolaşımı enfeksiyonu

$(\%)^{\star *}$ : Satı̈r yüzdesi,

MRKNS: Metisillin'e rezistan kogulaz negatif stafilokok, MRSA: Metisilin'e rezistan

Staphylococcus aureus, MDKNS: Metisilin'e duyarlı koagulaz negatif stafilokok.
Yapılan eğitim ve denetimler ile ilgili uzmanların da EKK ile uyumlu çalışmaları ve klavuzlara uygun davranılmasının buna yol açtığı düşünülmekle birlikte, 3. ve 5. yıllarda hiç olgu saptanamaması, o dönemlerde otomatize kan kültür sisteminin hastanemizde uygulanmamakta olması ve tanı eksikliği nedeni ile olabilir. RCYBÜ'de de benzer olarak ilk 3 yıl hem SVKKO'ları hem de SVKI-KDE hızları ortalamanın altında iken, son 2 yılda her ikisinin de paralel olarak arttığı (50-75-90) görülmüştür.

Yetmiş beş ülkede gerçekleştirilen EPIC II çalışmasında, YBÜ'lerinde en sık görülen HKE türleri sırasıyla; solunum yolu enfeksiyonları (\%64), kan dolaşımı enfeksiyonları (\%15) ve genitoüriner enfeksiyonlar (\%14) olarak bildirilmiştir (4). Ülkemizde yayınlanan bazı çalışmalarda da en sık görülen enfeksiyon türleri, pnomoni, bakteremi ve ÜSE olarak sıralanmaktadır $(5,22,23,26,30-33)$. Bizim çalışmamızda sıralama ÜKI-ÜSE (\%80), VIP (\%13) ve SVKI-KDE (\%7) şeklindedir. Benzer olarak HKE'ler içinde en sık ÜSE'lerinin bildirildiği çalışmalarda; Motor ve ark. ÜSE oranını \%47,1 (KDE \%36, VIP \%17), Erdoğan ve ark. ÜSE oranı \%65 (VIP ve KDE \%15'er), Geyik ve ark. da ÜSE: \%45 (VIP \%38, KDE \% 17), olarak bildirmişlerdir $(21,24,34)$. Bu üç çalışmada da ÜKKO'larının yüksek olması ortak bir nokta olarak göze çarpmaktaktadır. EPIC II çalışmasına benzer olarak, ülkemizde en sık VIP ardından KDE ve en seyrek ÜSE görüldüğü çalışmalar olduğu gibi $(22,23,33,35)$ bazı

\begin{tabular}{|c|c|c|c|c|c|}
\hline Etken & $\begin{array}{l}\text { vip } \\
\text { sayı }\end{array}$ & $\begin{array}{l}\text { ÜKi-ÜSE } \\
\text { sayı }\end{array}$ & $\begin{array}{l}\text { SVKi-KDE } \\
\text { sayı }\end{array}$ & $\begin{array}{l}\text { Toplam } \\
\text { sayı }\end{array}$ & $\begin{array}{l}178 \text { etken içinde \% } \\
\text { (\%)" }\end{array}$ \\
\hline E.coli & 4 & 37 & 2 & 43 & 24 \\
\hline E.coli dışı Enterobacteriacea türleri* & 3 & 23 & - & 26 & 15 \\
\hline Pseudomonas spp. & 5 & 17 & 1 & 23 & 13 \\
\hline Acinetobacter spp. & 7 & 5 & 1 & 13 & 7 \\
\hline MRKNS & 2 & 4 & 4 & 10 & 6 \\
\hline MRSA & 3 & 2 & 3 & 8 & 4 \\
\hline MDKNS & - & - & 1 & 1 & 1 \\
\hline Enterococcus spp. & - & 2 & - & 2 & 1 \\
\hline Candida spp. & - & 46 & - & 46 & 26 \\
\hline Etkeni saptanamayan & - & 6 & - & 6 & 3 \\
\hline Toplam:n/(\%)** & $24 / 13$ & $142 / 80$ & $12 / 7$ & 178 & 100 \\
\hline
\end{tabular}

iAiHE: İnvaziv araçla ilişkili hastane enfeksiyonu

ViP: Ventilatörle ilişkili pnomoni

ÜKi-ÜSE: Üriner kateterle ilişkili üriner sistem enfeksiyonu

SVKi-KDE: Santral venöz kateterle ilișkili kan dolașımı enfeksiyonu

*:E.coli dışı Enterobacteriacea türleri: Enterobacter aeroginosa: $(n)=13$, Klebsiella spp. $(n)=10$, Proteus spp. $(n)=1$, Serratia spp. $(n)=1$, Citrobacter freundii $(n)=1$.

$(\%)^{\star *}$ : Satır yüzdesi

(\%)": sütun yüzdesi

MRKNS: Metisilin'e rezistan kogulaz negatif stafilokok, MRSA: Metisilin'e rezistan Staphylococcus aureus, MDKNS: Metisilin'e duyarlı koagulaz negatif stafilokok. 


\begin{tabular}{|c|c|c|c|c|c|c|c|c|c|c|c|c|}
\hline Etken & SZDM & AM-SBT & TZB & iMP & Cip & AMiк & GENT & TRM-S & ERIT & CLiN & TETR & VA \\
\hline E.coli $n=43$ & 65 & 69 & 42 & 11 & 75 & 43 & 61 & 76 & - & - & - & - \\
\hline Enterobacter aerogenese $n=13$ & 92 & 84 & 61 & 28 & 83 & 77 & 60 & 92 & - & - & - & - \\
\hline Klebsiella spp. $n=10$ & 50 & 100 & 60 & 10 & 70 & 70 & 50 & 90 & - & - & - & - \\
\hline Proteus spp. $n=1$ & 0 & 0 & 0 & 0 & 0 & 100 & 100 & 0 & - & - & - & - \\
\hline Serratia spp. $n=1$ & 0 & 100 & 0 & 0 & 100 & 100 & 100 & 100 & - & - & - & - \\
\hline Citrobacter spp. $n=1$ & 100 & 100 & 0 & 0 & 0 & 100 & 100 & 0 & - & - & - & - \\
\hline Pseudomonas spp. $\mathrm{n}=23$ & 66 & 91 & 43 & 13 & 47 & 86 & 85 & - & - & - & - & - \\
\hline Acinetobacter spp. $n=13$ & 100 & 100 & 70 & 60 & 100 & 100 & 80 & - & - & - & - & - \\
\hline MRSA & - & 64 & - & - & 78 & 28 & 85 & - & 90 & 90 & 95 & $0 n=8$ \\
\hline MRKNS $n=10$ & - & 60 & - & - & 90 & 80 & 70 & - & 100 & 90 & 90 & 0 \\
\hline MDKNS n=1 & - & 0 & - & - & 100 & 0 & 0 & - & 100 & 100 & 100 & 0 \\
\hline Enterococcus spp. $n=2$ & - & 50 & - & - & 50 & 100 & 100 & - & 100 & - & - & 0 \\
\hline
\end{tabular}

IAiHE: Invaziv araçla ilişkili hastane enfeksiyonu

STZM:s eftazidim, AM-SBT: ampisillin-sulbaktam, TZB: piperasillin-tazobaktam, iMP: imipenem, CiP:c iprofloksasin, AMiK: amikasin, GENT: gentamisin, TRM-S: trimethoprim-metaksasol,

ERIT: eritromisin, CLIN: clindamisin, TETR: tetrasiklin, VA: vankomisin

\begin{tabular}{lll}
\hline \multicolumn{4}{l}{ Tablo 10. Ülkemizdeki bazı çalışmalarda bildirilen, YBÜ'lerindeki hastane kökenli enfeksiyon (HKE) hızları } \\
\hline Çalışmacılar & Kaynak no & HKE hızı \\
\hline 1- Üniversite Hastaneleri YBÜ'leri: & 19 & $1,6-47,4$ (en yüksek reanimasyon YBÜ'de:44.6) \\
İnan ve ark. & 20 & 36 \\
Arslan ve ark. & 21 & 16,9 \\
Motor ve ark. & 22 & 18 (anestezi YBÜ'de) \\
Akın ve ark. & 23 & 7 (anestezi YBÜ'de) \\
Meriç ve ark. & 24 & 15,8 (üç farklı YBÜ'de) \\
Erdoğan ve ark. & & 9,77 \\
2- Üçüncü basamak eğitim araştırma hastaneleri YBÜ'leri:: & 25 & \\
Pehlivanoğlu ve ark. & & 6,4 (beş farklı YBÜ'de) \\
3- İkinci basamak Devlet Hastaneleri YBÜ'leri: & 26 & $5,32-10,47$ (RCYBÜ-DYBÜ'nde) \\
Öncül ve ark. & &
\end{tabular}

YBÜ: yoğun bakım ünitesi

HKE :Hastane kökenli enfeksiyon, HKE hızı: IAiHE gelişen hasta sayısı/toplam izlenen hasta sayısıx100.

çalışmalarda en sık KDE, ardından VIP ve en seyrek ÜSE görüldüğü bildirilmekte $(26,28)$ ve her hastane kendi şartları içinde bu sonuçları açıklamaktadır. Bu durum da sürveyans verilerine göre, her hastanenin önceliklerinin farklı olabileceğini göstermektedir.

Bu çalışmada HKE tanısı alan hastaların risk durumları incelendiğinde, her iki YBÜ'de cinsiyet, yaş, yatış tanıları, hastalıklarının şiddeti skorlamaları, ortalama yoğun bakımda kalış süreleri ile invaziv araç kalış süreleri, araç kullanma oranlarının benzer olduğu buna rağmen yıllar içinde DYBÜ'de HKE oranlarının diğer üniteye göre nispeten yüksek olduğu görülmüștür. Bunun sebebinin iki ünitede fiziki ve beșeri şartlar da benzer olduğuna göre, DYBÜ'de enfeksiyon gelișen hastalarda altta yatan hastalıkların daha fazla olması (ileri yaş, 
Tablo 11. Ülkemizdeki bazı hastanelerin YBÜ'lerinde saptanan hastane enfeksiyonu insidans dansitesi (HEiD) sonuçları

\begin{tabular}{lll}
\hline Çalışmacılar & Kaynak no & HEiD \\
\hline $\begin{array}{l}\text { 1- Sağlık Bakanlı̆ına bağlı Devlet Hastaneleri veya eğitim araştırma hastaneleri } \\
\text { YBÜ'leri: }\end{array}$ & 27 & 12,7 (dahili ve cerrahi hastaların karma izlendiği YBÜ) \\
Akalın ve ark. & 28 & 21,6 ( invaziv araçl-araçsız tüm YBÜ enfeksiyonlarında) \\
Ak ve ark. & 29 & 19,51 \\
Çukurova ve ark. & 26 & $15 / 12.9 / 11 / 16.8$ (beş farklı YBÜ'de) \\
Öncül ve ark. & & \\
2- Üniversite hastaneleri YBÜ'leri: & 23 & 38 \\
Meriç ve ark. & 6 & 33,9 \\
Leblebicioğlu ve ark. & 22 & 58 (anestezi YBÜ'de araçlı ve araçSIZ tüm HE'da) \\
Akın ve ark. & 21 & 19,2 \\
Motor ve ark. & 24 & 26,5 \\
Erdoğan ve ark. & & $8,73 / 11,48 / 6,67$ (ortak, DYBÜ, RCYBÜ'de) \\
3- Bizim çalışmamız & &
\end{tabular}

YBÜ: yoğun bakım ünitesi

HEID: hastane enfeksiyonu insidans dansitesi, HEID: IAIHE atak sayısı/toplam izlem yapılan YBG sayısıx1000.

serebrovasküler ve solunum hastalıkları ile diabet ve malignite gibi) olabileceği düşünülmüştür. Her iki ünitede de HKE gelişen hastalarımızın hemen hemen tamamının uzun süreli invaziv araç kullanıyor olmaları da ekstrensek risk faktörü olarak dikkat çekici bulunmuştur. HKE gelişmeyen hastaların risk dağıımı bu çalışmada değerlendirilmediği için risk analizi yapılamamıştır.

Çalışmamızda her iki YBÜ'de 5 yılda elde edilen tüm IAIHE etkenlerinin \%59'unu Enterobacteriaceae türleri ile non fermantatif bakteriler olmak üzere Gram negatif basillerin, \%26'sını Candida türlerinin, \%12'sini de Gram pozitif kokların oluşturduğu görülmüştür. YBÜ'lerinde IAIHE temelli bir çok çalışmada Gram negatif mikroorganizmaların daha baskın olduğu bildirilmiştir $(3,6,24)$. Çalışmamızdaki enfeksiyon etkenlerinin spesifik bölgelere dağılımına bakıldığında, ÜKI-ÜSE ataklarında \%58 Gram negatif basiller, \%32 Candida türleri, \%6 Gram pozitif kokların etken olduğu görülmüştür. Benzer şekilde ÜSE ataklarında Gram negatif basiller (non fermantatifler dahil) ve candida türlerinin baskın olduğunu bildiren bir çok çalışma vardır $(3,21,22,24,26,34)$. Çalışmamızdaki VIP ataklarında, etkenlerin \%50'si Pseudomonas ve Acinetobacter türleri, $\% 29$ 'u Enterobacteriaecae türleri olmak üzere toplam \%79'unu Gram negatif basillerin, \%21'ini de Gram pozitif kokların oluşturduğu görülmüştür, sonuçlarımız yapılan pek çok çalışma ile benzer bulunmuştur $(3,22,24,26,28,34)$. SVKIKDE etkenlerimizin \%66'sını Gram pozitif koklar, \%17'sini
Acinetobacter ve Pseudomonas türleri, \%17'sini de E. coli oluşturmuştur. Ülkemizde yapılan pek çok çalışmada benzer olarak Gram pozitif kokların bu enfeksiyon türünde sık görüldüğü bildirilmiştir $(21,22,26,28,34,35)$.

Çalışmamızda saptanan etkenlerin antibiyotiklere direnç durumları incelendiğinde, karbapenem direncinin Acinetobacter türlerinde oldukça yüksek $(\% 60)$, bunun dışındaki Gram negatif basillerde \%0-\%28 arasında olduğu (Pseudomonas spp.de \%13) görülmüştür. Gram pozitif koklarda; antibiyotiklere yüksek oranda direnç görülürken, tüm Gram pozitif suşlar vankomisine duyarlı bulunmuştur. Yapılan pek çok çalışmada Acinetobacter suşlarında karbapenem direncinin giderek arttığı belirtilmekte olup, Akın ve ark. 2004'te A. baumannii'de $\% 42$ olan direnç oranlarının, 2008'de \%93'e çıktığını bildirmişlerdir (15). Motor ve ark.'nda bu oran \%91'dir (21). UHESA 2012 raporunda Sağlık Bakanlığı hastanelerinde Pseudomonas aeruginosa'da karbapenem direnci ortalaması $\% 30$ ve Acinetobacter baumannii'de \%79 olarak görülmekte olup (15), bizim sonuçlarımız her ikisi için de ortalamanın altındadır, bunun sebebi her iki YBÜ'müzün de ikinci basamak olup, çok komplike olguların yatırımaması ve EKK'nın kararı gereği kısıtlı antibiyotik kullanımı nedeniyle olabilir.

\section{Sonuç}

Hastanemizin YBÜ'lerinin 5 yıllık HKE hızları ve araç kullanma oranlarının ülkemizdeki benzer fiziki ve personel 
özellikleri taşıyan hastaneler ile benzer olduğu, |AIHE'de (özellikle ÜKI-ÜSE ve VIP ataklarında), en sık saptanan etkenlerin ülkemizdeki pek çok hastane gibi, pseudomonas ve acinetobacter dahil olmak üzere Gram negatif basiller olduğu, bu suşlarda da karbapenem direncinin ülke ortalamasının altında olduğu görülmektedir.

YBÜ'müzde yıllar içinde, fiziki şartların düzeltilmesi, Sağlık Bakanlığı tarafından yayınlanan referanslara uyumun sağlanması, hedefe yönelik aktif sürveyans ve geri bildirimlerin devamlı yapılması, el hijyeni ve izolasyon önlemlerininin arttıııması ile HKE hızlarının kısmen azaltıldığı görülmüştür.

\section{Çıkar Çatışması \\ Yazarlar herhangi bir çıkar çatışması bildirmemişlerdir. Ethics Committee Approval:}

Ethics committee approval was receiwed for this study from the ethics committee of Muğla Sıtkı Koçman University School of Medicine.

\section{Informed Concent:}

Written informed consent was obtained from patients or patients' relatives who participated in this study.

Authors contributions. Conceived and designed the experiments or case: AFA. Performed the experiments or case: MK, BÖ, AFA. Analyzed the data: AFA. Wrote the paper: AFA. All authors have read and approved the final manuscript.

Etik Komite Onayı: Bu çalışma için etik komite onayı Muğla Sıtkı Koçman Üniversitesi Tıp Fakültesi Etik komitesinden alınmıştır.

Hasta Onamı: Yazılı hasta onamı bu çalışmaya alınan hasta veya yakınlarından alınmıştır.

Yazar Katkıları: Çalışma fikrinin tasarlanması: AFA. Uygulama ve verilerin toplanması: MK, BÖ, AFA. Verilerin analizi: AFA. Yazının hazırlanması: AFA. Tüm yazarlar yazının son halini okumuş ve onaylamıştır.

\section{Kaynaklar}

1. Trilla A. Epidemiology of nosocomial infections in adult intensive care units. Intensive Care Med 1994;20 Suppl 3:S1-4

2. Karabey S. Hastane infeksiyonları sürveyansında güncel yaklaşımlar. Hastane Infeksiyonları Dergisi 2006;10:153-60.

3. Rosenthal VD, Maki DG, Salomao R, Moreno CA, Mehta Y, Higuera F, et al. Device associated nosocomial infections in 55 intensive care units of 8 developing countries. Ann Intern Med 2006;145:582-92.

4. Vincent JL, Rello J, Marshall J, Silva E, Anzueto A, Martin CD, et al. International study of the prevelance and out comes of infection in intensive care units. JAMA 2009;302:2323-9.

5. Meriç M, Baykara N, Aksoy S, Kol IO, Yılmaz G, Beyazit N, et al. Epidemiology and risk factors of intensive care unite acquired infections: a prospective multicentre cohort study in a middle-income country. Singapore Med J 2012;53:260-3.

6. Leblebicioğlu H, Rosenthal VD, Arıkan OA, Özgültekin A, Yalçın AN, Köksal l, et al. Device-associated hospital-acquired infection rates in Turkish intensive care units. Findings of the International Nosocomial Infection Control Consortium(INICC). J Hosp Infect 2007;65:251-7.

7. National Healthcare Safety Network(NHSN) report: Data summary for 2006 through 2008, issued December 2009 Jonathan R. Edwards, MStat, Kelly D. Peterson, BBA, Yi mu at al. Published by the Association for Professionals in Infection Control and Epidemiology, Inc. Am J Infect Control 2009;37:783-805.
8. National Healthcare Safety Network(NHSN) report, data summary for 2009, device-associated module. Margaret A.Dudeck, MPH, CPH, Teresa C. Horan, Kelly D. Peterson, BBA, Katherine Allen-Bridson, RN, BSN, CIC, Gloria C.Morrell, RN, MS, MSN, CIC, Daniel A.Pollock, $M D$, and Jonathan R. Edwards, MStat Atlanta, Georgia.Am J Infect Control 2011;39:349-67.

9. National Healthcare Safety Network(NHSN) Report, data summary for 2010 , device-associated module. Margaret A. Dudeck, MPH, $\mathrm{CPH}$, Teresa C. Horan, $\mathrm{MPH}$, Kelly D. Peterson, BBA, Katherine Allen-Bridson, RN, BSN, MScPH, CIC, Gloria Morrell, RN, MS, MSN, CIC, Daniel A.Pollock, MD, and Jonathan R. Edwards, MStat Atlanta, Georgia. Published by Elsevier Inc.on behalf of the Association for Professionals in Infection Control and Epidemiology, Inc. Am J Infect Control 2011;798-816.

10. National Healthcare Safety Network(NHSN) report, data summary for 2011, device-associated module. Margaret A.Dudeck, MPH, CPH, Teresa C. Horan, $\mathrm{MPH}$, Kelly D. Peterson, BBA, Katherine Allen-Bridson, RN, BSN, MScPH, CIC, Gloria Morrell, RN, MS, MSN, CIC, Angela Anttila, RN, MSN, NPC, CIC, Daniel A.Pollock, MD, and Jonathan R. Edwards, MStat. Division of healthcare Quality Promotion, National Center for Emerging, zoonotic, and Infectious Diseases, Centers for Disease Control and Prevention. Public Health Service, US Department of Health and Human Services, Atlanta, GA Am J Infection Control 2013;41:286-300.
11. National Healthcare Safety Network (NHSN) report, data summary for 2012, Device-associated module. Margaret A.Dudeck, MPH, Lindsey M.Weiner $\mathrm{MPH}$, Katherine Allen-Bridson, RN, BSN, $\mathrm{MscPH}$, Paul J. Malpiedi MPH, Kelly D. Peterson, BBA, Daniel A.Pollock MD, Daun M Sievert PhD. Division of healthcare Quality Promotion, National Center for Emerging, zoonotic, and Infectious Diseases, Centers for Disease Control and Prevention. Public Health Service, US Department of Health and Human Services, Atlanta, GA. Am J Infection Control 2013;41:1148-1166.

12. Ulusal Hastane Enfeksiyonları Surveyans Ağı(UHESA) raporu özet veri, 20082009. Refik Saydam Hifsısıhha Merkezi Başkanlığı Ulusal hastane infeksiyonları sürveyans ve kontrol birimi, Ekim 2011. http://hastaneenfeksiyonlari.saglik.gov.tr/ dosya/2008_2009.pdf.

13. Ulusal Hastane Enfeksiyonları Surveyans Ağı(UHESA) raporu özet veri, 2010. Refik Saydam Hıfsısıhha Merkezi Başkanlığı Ulusal Hastane Infeksiyonları Sürveyans ve Kontrol Birimi, Eylül 2011. htpp//www. rshm.gov.tr/enfeksiyon/dosya/2010 PAPOR pdf

14. Ulusal Hastane Enfeksiyonları Surveyans Ağı(UHESA) raporu özet veri, 2011. TC Sağlık Bakanlığı Sağlık Hizmetleri Genel Müdürlüğü Sağlık Hizmet Standartları Dairesi Bașkanlığı, Nisan 2013. http:// uhes.saglik.gov.tr./ public/indir/UHESAANALIZ.2011.pdf. 
15. Ulusal Hastane Enfeksiyonları Surveyans Ağı(UHESA) raporu özet veri, 2012. TC Sağlık Bakanlığı Sağlık Hizmetleri Genel Müdürlüğü Sağlık Hizmet Standartları Dairesi Başkanlığı, Nisan 2013. http:// uhes.saglik.gov.tr./ public/indir/UHESAANALIZ.2012.pdf.

16. Horan TC, Andrus M, Dudeck MA. CDC/ NHSN surveillance definition of healthcare-associated infection and criteria for specific types of infections in the acute care settings. Am J Infect Control 2008;36:309-32.

17. Spencer RC. Epidemiology of infection in ICUs. Intensive Care Med 1994;20 suppl 4:S2-S6.

18. Esen S, Leblebicioğlu H. Prevalence of nosocomial infections at intensive care units in Turkey: a multicentre 1.day point prevalence study. Scand J Infect Dis 2004;36:144-8

19. Inan D, Saba R, Keskin S, Öğünç D, Çiftçi C, Günserpen F, ve ark. Akdeniz Üniversitesi Hastanesi Yoğun bakım ünitelerinde hastane infeksiyonları. Yoğun Bakım Dergisi 2002;2:129-35.

20. Arslan H, Gürdoğan K. Yoğun bakım ünitesinde görülen hastane infeksiyonları. Hastane Infeksiyon Derg 1999;3:165-70.

21. Motor VK, Evirgen Ö, Yula E, Erden EŞ, Ocak S, Önlen Y. Mustafa Kemal Üniversitesi Tıp Fakültesi yoğun bakım ünitesinde 2011 yılında sağlık hizmeti ile ilişkili infeksiyonların değerlendirilmesi. Ankem Derg 2012;26:137-42.
22. Akın A, Çoruh AE, Alp E, Canpolat DG. Anestezi yoğun bakım ünitesinde beş yıl içerisinde gelişen nozokomiyal enfeksiyonlarda antibiyotik direncinin değerlendirilmesi. Erciyes Tıp Derg online 2011;33:1-6.

23. Meriç M, Willke A, Baykara Z N. Kocaeli Üniversitesi Hastanesi yoğun bakım ünitesinde alet kullanımı ile ilişkili infeksiyonlar: dört yıllık surveyans verileri. Klimik Derg 2007:20:83-7

24. Erdoğan H, Akan D, Ergin F, Erdoğan A, Arslan H. Yoğun bakım ünitesinde invaziv alet kullanımı ile ilişkili nozokomiyal infeksiyon hızları. Hastane infeksiyonları Derg 2005;9:107-12.

25. Pehlivanoğlu F, Yaşar KK, Bilir YA, Şengöz G, Güngör N, Nazlıcan Ö. 550 Yataklı Bir Araştırma hastanesinin Yoğun Bakım Ünitesinde 2009 Yılı Aletle Illişkili Hastane Enfeksiyonları Sürveyansı.Özgün Araştırma. Haseki Tıp Bülteni 2011;49:30-3.

26. Öncül A, Koçulu S, Elevli K. Bir Devlet Hastanesi'nin yoğun bakım ünitelerinde kazanılan hastane enfeksiyonlarının epidemiyolojisi. Şişli Etfal Hastansi Tıp Bülteni 2012;46:61-2.

27. Akalın Ș, Erkaya N, Göncü F. Yoğun bakım ünitesinde hastane infeksiyonlarının epidemiyoljisi. Hastane Infeksiyonları Derg 2009:13:150-4.

28. Ak O, Batırel A, Ozer S, Colakoglu S. Nosocomial infections and risk factors in the intensive care unit of a teaching and research hospital: A prospective cohort study. Med Sci Monit 2011;17:29-34.
29. Çukurova Z, Durdu B, Hergünsel O, Eren G, Tekdöş Y, Durdu Y. Yoğun bakım kliniğinde invaziv araç ilişkili hastane enfeksiyonları surveyansı. Türkiye Klinikleri Tıp Bilimleri Derg 2012;32:438-43.

30. Göktaş U, Yaman G, Karahocagil MK, Bilici A, Katı I, Berktaş M. Anestezi yoğun bakım ünitesinde hastane infeksiyonu etkenleri ve direnç profillerinin değerIendirilmesi. J Turk Soc Int Care Med 2010;8:13-7.

31. Çetinkaya Ş Y, Aşçıŏlu S, Büke Ç. Yoğun bakım ünitelerinde hastane infeksiyonlarının prevelansı: çok merkezli bir nokta prevelans çalışması. Hastane Infeksiyonları Derg 2006;10(Ek 1):33-4.

32. Gürbüz $A$, Sungurtekin $H$, Gürbüz $M$, Kaleli I. Anestezi yoğun bakım ünitesinde görülen hastane infeksiyonları . J Turk Soc Int Care Med 2010;8:6-12.

33. Kaya S, Yılmaz G, Çakır E, Alioğlu Z, Bayramoğlu G, Köksal I. Device -associated hospital infections in neurology-neurosurgery intensive care unit of technical university faculty of medicine. Journal of Neurological Sciences(Turkish) 2010;27:377-85.

34. Geyik M F, Üstün C, Hoşoğlu S, Çelen M K, Ayaz C. Dicle Üniversitesi Hastanesinde alet ilişkili hastane infeksiyonları. Ankem Derg 2007;21:150-4.

35. Saçar S, Kavas S T, Asan A, Cevahir N, Serin S, Turgut H. Pamukkale Üniversitesi Hastanesi'nde hastane infeksiyonları sürveyansı. Infeksiyon Derg 2008;22:15-21. 